FEDERAL RESERVE BANK OF SAN FRANCISCO

WORKING PAPER SERIES

\title{
The Frequency of Price Adjustment Viewed Through the Lens of Aggregate Data
}

\author{
Richard Dennis \\ Federal Reserve Bank of San Francisco
}

November 2009

Working Paper 2006-22

http://www.frbsf.org/publications/economics/papers/2006/wp06-22bk.pdf

The views in this paper are solely the responsibility of the authors and should not be interpreted as reflecting the views of the Federal Reserve Bank of San Francisco or the Board of Governors of the Federal Reserve System. 


\title{
The Frequency of Price Adjustment Viewed through the Lens of Aggregate Data*
}

\author{
Richard Dennis ${ }^{\dagger}$ \\ Federal Reserve Bank of San Francisco
}

November, 2009

\begin{abstract}
The Calvo pricing model that lies at the heart of many New Keynesian business cycle models has been roundly criticized for being inconsistent both with time series data on inflation and with micro-data on the frequency of price changes. In this paper I develop a new pricing model whose structure can be interpreted in terms of menu costs and information gathering/processing costs, that usefully recognizes both criticisms. The resulting Phillips curve encompasses the partial-indexation model, the full-indexation model, and the Calvo model, and can speak to micro-data in ways that these models cannot. Taking the Phillips curve to the data, I find that the share of firms that change prices each quarter is about 60 percent and, perhaps reflecting the importance of information gathering/processing costs, that price indexation is important for inflation dynamics.
\end{abstract}

Keywords: Price adjustment, inflation indexation, Bayesian estimation.

JEL Classification: C11, C52, E31, E52.

\footnotetext{
${ }^{*}$ I would like to thank seminar participants at Bocconi University, the Federal Reserve Bank of San Francisco, Tokyo University, the Reserve Bank of New Zealand, Boston College, and the Royal Economic Society conference, 2007, for comments. The views expressed in this paper do not necessarily reflect those of the Federal Reserve Bank of San Francisco or the Federal Reserve System.

${ }^{\dagger}$ Address for Correspondence: Economic Research, Mail Stop 1130, Federal Reserve Bank of San Francisco, 101 Market St, CA 94105, USA. Email: richard.dennis@sf.frb.org.
} 


\section{Introduction}

New Keynesian business cycle models have become the dominant framework for studying the design and conduct of monetary policy. The models formalize the rigidities and market imperfections that govern their behavior and are micro-founded, which permits welfare analysis and makes policy experiments conducted within them less susceptible to the Lucas (1976) critique. Prominent examples in the New Keynesian tradition include Rotemberg and Woodford (1997), Clarida, Galí, and Gertler (1999), McCallum and Nelson (1999), Walsh (2003), and Woodford (2003). One of the most important components in these models is the New Keynesian Phillips curve, the equation linking inflation to marginal costs that provides a stabilization role for monetary policy. The "micro-structure" that is most widely used to derive the New Keynesian Phillips curve is the Calvo model ${ }^{1}$ (Calvo, 1983), and the defining feature of this model is that only a fixed (Calvo-) share of firms have the opportunity to optimize their prices each period. This Calvo-share parameter governs the frequency with which firms change prices and determines the average duration between price changes.

Despite its popularity, the New Keynesian Phillips curve has attracted considerable criticism. Some criticisms are empirical; Estrella and Fuhrer (2002) argue that the New Keynesian Phillips curve provides a poor description of inflation dynamics because it asserts a correlation structure among inflation, the change in inflation, and marginal costs that prevents it from replicating the hump-shaped responses that are widely recognized to characterize inflation's behavior following shocks. Similarly, Rudd and Whelan (2006) argue that the New Keynesian Phillips curve is incapable of describing inflation dynamics and suggest that there is little evidence of the type of forward-looking behavior required by the model. Other criticisms focus on whether estimates of the New Keynesian Phillips curve are economically plausible. In this vein, a prominent criticism is that Calvo-shares estimated from the New Keynesian Phillips curve imply a level of price rigidity that is inconsistent with micro-data on the frequency of price adjustment. For example, Eichenbaum and Fisher (2007) estimate the Calvo-share to be around 0.85 for the United States, which implies that only 15 percent of firms change their prices each quarter and that firms change prices once every 20 months on average. But after examining Bureau of Labor Statistics data on price changes - the very price data that go into the consumer price index and the personal consumption expenditures price index — Bils

\footnotetext{
${ }^{1}$ Roberts (1995) shows that Rotemberg's (1982) quadratic price adjustment costs model and Taylor's (1980) overlapping nominal wage contracts model give rise to closely related specifications, so the issues discussed in this paper apply equally to these models. Gertler and Leahy (2008) derive the New Keynesian Phillips curve from a state-contingent pricing microfoundation.
} 
and Klenow (2004) and Nakamura and Steinsson (2008) report that, excluding temporary sales, the average duration between price changes for the expenditure-weighted median good is 5.5 months and 8.6 months, respectively. The disparity between estimates of the Calvoshare and micro-evidence on the frequency of price adjustment is worrisome, particularly since models built around the New Keynesian Phillips curve are routinely used to address issues as important as how to design a welfare-maximizing monetary policy.

In this paper, I develop a new model of price setting, building on Calvo (1983). An essential feature of this model is that, although a share of firms have the opportunity to change prices each period, they do not necessarily make an optimal price change. Instead, among those firms that change prices a fraction makes an optimal price change, while the remainder employ an indexation pricing strategy. In this model, firms, each period, find themselves randomly distributed among the three pricing states: a firm can keep their price unchanged; a firm can index their price; or a firm can set its price optimally. Importantly, all three pricing states are internalized by price-setting firms.

Why is this price-setting environment attractive? Where traditional models of price adjustment have emphasized physical costs to changing prices, such as menu costs, as the source of price rigidity (Mankiw, 1985), recent literature has emphasized the costs that firms face when gathering (Mankiw and Reis, 2002) and processing (Sims, 2003; Woodford, 2008) the information they require in order to set prices optimally. In fact, some evidence suggests that costs to gathering and processing information and company managerial and organizational issues (Zbaraki, Ritson, Levy, Dutta, and Bergin, 2004; Zbaraki, Levy, and Bergin, 2007) may be much more important for price setting than traditional menu cost factors. An attractive aspect of the price-setting environment developed in this paper is that it provides a vehicle through which both costs can play a role. Menu costs - which are incurred whether or not a price change is optimal - are associated with the share of firms that can change prices. When these menu costs are large, a smaller share of firms is likely to change their prices. Similarly, costs to gathering and processing information are associated with the share of price changers that use price indexation. When the costs to gathering and processing information are high, a larger share of price-changing firms might resort to an indexation-based pricing strategy.

After describing the model, I derive its associated Phillips curve, highlighting its connections to the New Keynesian Phillips curve and to the full- and partial-indexation Phillips curves. Specifically, I show that these alternatives are all special cases of the Phillips curve I derive. Subsequently, I develop a small-scale New Keynesian business cycle model and 
estimate specifications based on the Phillips curve I derive, the Calvo Phillips curve, the fullindexation Phillips curve, and the Galí-Gertler Phillips curve (Galí and Gertler, 1999). The results are striking. First, whereas estimates of the New Keynesian Phillips curve imply an average duration between price changes that is clearly inconsistent with Bureau of Labor Statistics price data, the model I develop does much better. In fact, my results place the share of firms that change prices each quarter at about 60 percent, suggesting relatively frequent price adjustment. Second, although firms change prices frequently, I find that the data want the majority of these firms use price indexation, consistent with the view that factors such as information gathering/processing costs may be extremely important for price setting.

This paper is related to the interesting study by Dupor, Kitamura, and Tsuruga (2008), who develop a Phillips curve that integrates sticky information (Mankiw and Reis, 2002) with sticky prices (Calvo, 1983). Dupor, Kitamura, and Tsuruga (2008) assume that the fixed share of firms that can update their prices each period is independent of the fixed share of firms can update their information set to derive a Phillips curve that contains a role for both menu costs and information-gathering costs. They show that their specification is related closely to a hybrid New Keynesian Phillips curve, but with an additional term to allow for the distribution of information across "inattentive" firms. Despite its similar motivation, their estimation suggests that only 14 percent of firms change their prices each quarter, but that 42 percent of firms update their information sets. Empirically, therefore, their specification, much like the Calvo Phillips curve, implies relatively infrequent price adjustment and suggests that menu costs may be more important for firms pricing than information-gathering costs.

I begin by describing the New Keynesian Phillips curve and illustrating the empirical disparity between the Calvo-share and the frequency of price adjustment implied by microdata. Section 3 outlines the economic environment that underlies my model and derives the associated Phillips curve. Section 4 compares the model to the Calvo model, the fullindexation model, and the partial-indexation model and proves its isomorphism with the partial-indexation model. Section 5 develops a small-scale New Keynesian business cycle model suitable for estimation, describes the data, and discusses the estimation strategy. Section 6 presents and interprets the estimates and compares them to those obtained from alternative pricing models. Section 7 concludes. 


\section{The New Keynesian Phillips curve and price rigidity}

As noted in the introduction, the centerpiece to much business cycle and policy analysis is the New Keynesian Phillips curve

$$
\widehat{\pi}_{t}=\beta \mathrm{E}_{t} \widehat{\pi}_{t+1}+\frac{(1-\xi)(1-\beta \xi)}{\xi} \widehat{m c}_{t},
$$

where $\widehat{\pi}_{t}$ and $\widehat{m c}_{t}$ represent the percentage point deviation of inflation, $\pi_{t}$, and the percent deviation of real marginal costs, $m c_{t}$, around their zero-inflation nonstochastic steady state values, respectively. An economic environment that gives rise to this Phillips curve is one in which firms are monopolistically competitive, renting capital and labor and setting their prices to maximize profits subject to a constant elasticity of substitution demand curve, a Cobb-Douglas production technology, and a price rigidity, á la Calvo (1983). ${ }^{2}$ In equation (1), $\beta \in(0,1)$ is the subjective discount factor and $\xi \in(0,1)$ is the Calvo-share, the share of firms that cannot optimize their prices each period.

With regard to suitable values for $\xi$, a touchstone in the literature is Blinder (1994), who surveyed firms on the frequency of their price changes. Based on Blinder's (1994) survey, Rotemberg and Woodford (1997) set $\xi=0.66$, which implies an average duration between price changes of nine months. But many calibration studies have assumed that prices change somewhat less frequently than this. For example, Erceg, Henderson, and Levin (2000) and Liu and Phaneuf (2007) each set $\xi=0.75$, implying an average duration between price changes of 12 months.

Among studies that estimate $\xi$, a popular approach is to apply a generalized method of moments estimator to the moment condition ${ }^{3}$

$$
\mathrm{E}_{t}\left[\left(\widehat{\pi}_{t}-\beta \widehat{\pi}_{t+1}-\frac{(1-\xi)(1-\beta \xi)}{\xi} \widehat{m c}_{t}\right) \mathbf{z}_{t}\right]=0
$$

where $\mathbf{z}_{t}$ is a vector containing econometric instruments. This is the approach taken by Galí and Gertler (1999), Galí, Gertler, and López-Salido (2001), Eichenbaum and Fisher (2004), Jung and Yun (2005), and Ravenna and Walsh (2006). An alternative method is to iterate forward over equation (1) and combine the result with an evolution process for real marginal costs to produce an estimable expression relating inflation to real marginal costs (Sbordone,

\footnotetext{
${ }^{2}$ Gertler and Leahy (2008) provide an alternative derivation that is based on state-contingent pricing.

${ }^{3}$ An alternative moment condition that is often used is equation (2) multiplied through by $\xi$. Some of the estimates shown in Table 1 come from this alternative moment condition.
} 
2002). A range of estimates of $\xi$ for the U.S., all obtained from the moment condition (equation (2)), are displayed in Table $1 .{ }^{4}$

\begin{tabular}{c|c|c}
\hline \hline \multicolumn{3}{c}{ Table 1: Estimates of the New Keynesian Phillips Curve } \\
\hline Study & Sample & $\xi$ \\
\hline Galí \& Gertler (1999) & $1960: 1-1997: 4$ & $0.829-0.884$ \\
Galí, Gertler \& López-Salido (2001) & $1970: 1-1998: 4$ & $0.845-0.867$ \\
Sbordone (2002) & $1960: 2-1997: 1$ & 0.792 \\
Eichenbaum \& Fisher (2004) & $1959: 1-2001: 4$ & $0.87-0.91$ \\
Jung \& Yun (2005) & $1967: 1-2004: 4$ & 0.910 \\
Ravenna \& Walsh (2006) & $1960: 1-2001: 1$ & $0.758-0.911$ \\
\hline \hline
\end{tabular}

The estimates of $\xi$ shown in Table 1 vary from a low of 0.758 to a high of 0.911 . While $\xi=0.758$ is broadly on par with the value used in calibration studies, a value such as $\xi=0.911$ is much larger than either the values used in calibration exercises or the value implied by Blinder's (1994) study. The average value for $\xi$ in Table 1 is in the order of 0.85 , suggesting that firms only change prices once every 20 months. The estimates in Table 1 highlight what has become an important criticism of the New Keynesian Phillips curve, which is that estimates of $\xi$ are too large, implying average durations between price changes that are inconsistent with micro-evidence on the frequency of price adjustment (Bils and Klenow, 2004; Nakamura and Steinsson, 2008). ${ }^{5}$

\subsection{Strategic complementarity and firm-specific capital}

One way to resolve the apparent inconsistency between macro- and micro-estimates of the frequency of price adjustment is to change the pricing environment to allow for factors such as strategic complementarity (Woodford, 2003) and/or firm-specific capital (Sbordone, 2002). These changes add one or more structural parameters to the coefficient on real marginal costs, thereby permitting greater flexibility with respect to the choice of $\xi$. Unfortunately, because these modifications leave the Phillips curve's structure unchanged, they cannot, in isolation, overcome the criticism that the New Keynesian Phillips curve provides a poor description of inflation dynamics (Estrella and Fuhrer, 2002; Rudd and Whelan, 2006).

\footnotetext{
${ }^{4}$ All of the estimates reported in Table 1 have been made consistent with a Cobb-Douglas production technology and rental markets for capital and labor, facilitating comparison across studies by making the estimates invariant to particular assumptions about the steady state markup and labor's share of income. However, the values shown may differ from those reported in the original papers as a consequence. With respect to Sbordone's estimates, the best-fitting specification in Sbordone (2002, Table 2) has a coefficient on real marginal costs equaling $\frac{1}{18.3}$. Using Sbordone's assumption about the discount factor and assuming a rental market for capital, the implied value for $\xi$ is 0.792 .

${ }^{5}$ Of course, there are other notable studies that look at micro-data on the frequency of price adjustment, including Cecchetti (1986), Carlton (1986), and Kashyap (1995).
} 


\section{A new pricing model}

Firms are assumed to be monopolistically competitive and to produce according to a constantreturns-to-scale production technology subject to a downward-sloping demand schedule. In the spirit of Calvo (1983), not all firms can change their prices each period, and, in the spirit of Christiano, Eichenbaum, and Evans (2005), not all price changes that do occur are chosen optimally. However, unlike Calvo (1983), in which firms either set their prices optimally or keep their prices unchanged, and unlike Christiano, Eichenbaum, and Evans (2005), in which firms either set their prices optimally or index their prices to past inflation, in the model developed here firms are randomly allocated among three pricing states. Depending on draws from two independent Bernoulli distributions, a firm either sets its price optimally, sets its price using an indexation rule, or keeps its price unchanged. Informally, the parameters that govern the share of firms allocated to each pricing state can be interpreted in terms of menu costs and the costs associated with gathering and processing the information needed to set prices optimally. To identify this model in subsequent discussion, I refer to it as the generalized-Calvo model.

The model developed below is also related to one developed by Galí and Gertler (1999);

the two models share the three distinct pricing strategies outlined above. However, there are several important differences between the two models. One important difference is that firms in the generalized-Calvo model internalize the three pricing strategies when optimizing their price. In contrast, optimizing firms in the Galí-Gertler model behave like those in the Calvo (1983) model. Thus, where all firms are identical and are allocated randomly among pricing states in the model developed here, in the Galí-Gertler model there are two distinct types of firm: Calvo price-setters and rule-of-thumb price-setters. Another difference is that where the Galí-Gertler model contains rule-of-thumb price-setters the model developed below is built around price indexation.

\subsection{Basic structure}

The economy is populated by a unit-measure continuum of monopolistically competitive firms. The $i$ 'th firm, $i \in[0,1]$, produces its differentiated product according to the Cobb-Douglas production technology

$$
y_{t}(i)=\left[e^{u_{t}} l_{t}(i)\right]^{\kappa} k_{t}(i)^{1-\kappa}
$$


$\kappa \in(0,1)$, where $e^{u_{t}}$ is an aggregate labor-augmenting technology shock and $y_{t}(i), l_{t}(i)$, and $k_{t}(i)$ denote the $i$ 'th firm's output, labor, and capital, respectively. Firms rent capital and hire labor in perfectly competitive markets and, because they face identical factor prices, employ capital and labor in the same ratio and share the same real marginal cost, i.e., $m c_{t}(i)=m c_{t}$, $\forall i \in[0,1]$.

A final good, $Y_{t}$, is produced from the outputs of the monopolistically competitive firms according to the Dixit and Stiglitz (1977) constant-returns-to-scale production technology

$$
Y_{t}=\left[\int_{0}^{1} y_{t}(i)^{\frac{\epsilon-1}{\epsilon}} d i\right]^{\frac{\epsilon}{\epsilon-1}}
$$

where $\epsilon \in(1, \infty)$ is the elasticity of substitution between intermediate goods. Final goods are used for consumption and investment and are sold to households in a perfectly competitive market. Efficient production of the final good implies that the demand schedule for the $i$ 'th firm's output takes the form

$$
y_{t}(i)=Y_{t}\left(\frac{P_{t}(i)}{P_{t}}\right)^{-\epsilon},
$$

where $P_{t}(i)$ is the price charged by the $i$ 'th firm and $P_{t}$ is the aggregate price index, the price of the final good.

Each period a fixed proportion of firms, $1-\theta, \theta \in[0,1)$, are able to change prices. However, not all firms that change prices do so optimally. Within the share of firms that change prices, a fixed proportion, $1-\omega, \omega \in[0,1)$, change their prices optimally, while the remaining proportion, $\omega$, set their prices using the indexation rule

$$
P_{t}(i)=\left(1+\pi_{t-1}\right) P_{t-1}(i)
$$

where $\pi_{t}$ denotes the inflation rate of the final good. Unlike the Calvo model, in which firms either set their prices optimally or keep their prices unchanged, here firms are distributed among three pricing states. Specifically, each period a measure equaling $\theta$ of firms do not change their prices, a measure equaling $\omega(1-\theta)$ of firms change their prices using the indexation rule, and a measure equaling $(1-\omega)(1-\theta)$ of firms set their prices to maximize expected discounted profits, with firms falling randomly into one of these three pricing states independently of their history of price changes.

To interpret this pricing structure, note that $\theta$ and $\omega$ can each be associated informally with a distinct cost impinging on the firm's pricing decision. The first set of costs, menu costs, are borne by firms when they change prices, regardless of whether the price change is optimal 
or not; these costs are associated with $\theta$. The second set of costs are those connected to the information gathering (Mankiw and Reis, 2002) and information processing (Sims, 2003) needed to determine the optimal price; these costs are associated with $\omega$. Importantly, $\theta$, which represents a cost to changing prices, determines the share of firms that change prices, not the share of firms that set their prices optimally. Because estimates of the frequency of price adjustment obtained from micro-data, such as Bils and Klenow (2004) and Nakamura and Steinsson (2008), are based on observed price changes, their findings are best interpreted as estimates of $\theta$, the proportion of firms that change prices, rather than as estimates of $(1-\omega)(1-\theta)$, the proportion of firms that change prices optimally.

The Phillips curve derived below is obtained by approximating the model around a zeroinflation steady state. In Appendix B, I treat the more general case in which the approximation is taken around a non-zero-inflation steady state and show that plausible values for steady state inflation do not have a large effect on the Phillips curve's coefficients.

\subsection{The Dixit-Stiglitz aggregate price}

With the indexation rule given by equation (6), I show in Appendix A that the aggregate price, the price of the final good, equals

$$
\begin{aligned}
P_{t} & \equiv\left[\int_{0}^{1} P_{t}(i)^{1-\epsilon} d i\right]^{\frac{1}{1-\epsilon}}, \\
& =\left[(1-\theta)(1-\omega) P_{t}^{* 1-\epsilon}+\omega(1-\theta)\left(1+\pi_{t-1}\right)^{1-\epsilon} P_{t-1}^{1-\epsilon}+\theta P_{t-1}^{1-\epsilon}\right]^{\frac{1}{1-\epsilon}}
\end{aligned}
$$

where $P_{t}^{*}$ is the price chosen by firms that can set their price optimally. ${ }^{6}$ Log-linearizing equation (7) around a zero-inflation steady state, the quasi-difference in aggregate inflation is related to the optimal relative price according to

$$
\widehat{\pi}_{t}=\frac{\omega(1-\theta)}{\theta+\omega(1-\theta)} \widehat{\pi}_{t-1}+\frac{(1-\omega)(1-\theta)}{\theta+\omega(1-\theta)} \widehat{p}_{t}^{*}
$$

where $\widehat{p}_{t}^{*}$ denotes the percent deviation in $p_{t}^{*}$ from $\bar{p}^{*}=1$. Conditional on $\widehat{p}_{t}^{*}$, equation (8) implies that the correlation between inflation and its lag is an increasing function of $\omega$ and a decreasing function of $\theta$. Further, conditional on lagged inflation, equation (8) implies that the correlation between $\pi_{t}$ and $\widehat{p}_{t}^{*}$ is a decreasing function of $\theta$ and $\omega$.

\footnotetext{
${ }^{6}$ Because real marginal costs are the same for all firms, in a symmetric equilibrium, firms that can set their price optimally will all choose the same price.
} 


\subsection{The pricing decision}

I assume that $\omega+\theta>0$, ruling out the case where all prices are flexible, but not ruling out the case where all firms change prices $(\theta=0)$ or the case where all price-changing firms optimize $(\omega=0)$. With this assumption, in period $t+1$ a firm that cannot optimize its price between period $t$ and period $t+1$ will expect to charge the price

$$
\begin{aligned}
P_{t+1}(i) & =P_{t}(i)\left[\frac{\omega(1-\theta)}{\theta+\omega(1-\theta)}\left(1+\pi_{t}\right)+\frac{\theta}{\theta+\omega(1-\theta)}\right], \\
& \equiv P_{t}(i) S_{t+1}
\end{aligned}
$$

where the two terms in equation (9) correspond to the two non-optimizing pricing states, with each state weighted by its conditional probability. Iterating forward over equation (9), a firm that cannot optimally set its price will expect in period $t+j$ to charge the price

$$
P_{t+j}(i)=P_{t}(i) \prod_{k=1}^{j} S_{t+k}
$$

Turning to the decision problem facing firms that can choose their price, in light of equation (10) these firms will choose $P_{t}(i)$ to maximize

$$
\mathrm{E}_{t} \sum_{j=0}^{\infty}(\beta \mu)^{j} \frac{\lambda_{t+j}}{\lambda_{t}} Y_{t+j}\left[\left(\frac{P_{t}(i) \prod_{k=1}^{j} S_{t+k}}{P_{t+j}}\right)^{1-\epsilon}-m c_{t+j}\left(\frac{P_{t}(i) \prod_{k=1}^{j} S_{t+k}}{P_{t+j}}\right)^{-\epsilon}\right],
$$

where $\mu \equiv \theta+\omega(1-\theta)$ denotes the share of firms that cannot optimize their prices and $\lambda_{t}$ is a shadow price representing the marginal utility of consumption in period $t$.

Differentiating equation (11) with respect to $P_{t}(i)$, the resulting first-order condition is

$$
\mathrm{E}_{t} \sum_{j=0}^{\infty}(\beta \mu)^{j} \frac{\lambda_{t+j}}{\lambda_{t}} y_{t+j}(i)\left[\frac{p_{t}^{*}(i)\left(\prod_{k=1}^{j} S_{t+k}\right)}{\prod_{k=1}^{j}\left(1+\pi_{t+k}\right)}-\frac{\epsilon}{(\epsilon-1)} m c_{t+j}\right]=0,
$$

which, when log-linearized around a zero-inflation steady state, yields

$$
\widehat{p}_{t}^{*}=\beta \mu \mathrm{E}_{t} \widehat{p}_{t+1}^{*}+\beta \mu\left(\mathrm{E}_{t} \pi_{t+1}-\frac{\omega(1-\theta)}{\mu} \pi_{t}\right)+(1-\beta \mu) \widehat{m c}_{t} .
$$

Equation (13) establishes that, in addition to real marginal costs and its expected future price, the firm's pricing decision is shaped by current and expected future inflation. Because $\mu$ is increasing in both $\theta$ and $\omega$, it is clear from equation (13) that increases in $\theta$ and $\omega$ raise the importance of future prices and lower the importance of current real marginal costs for the price chosen today. 


\subsection{The Phillips curve}

To derive the Phillips curve, I combine equations (8) and (13) to obtain the expression

$$
\begin{aligned}
\widehat{\pi}_{t}= & \frac{\omega(1-\theta)}{\theta+\omega(1-\theta)(1+\beta)} \widehat{\pi}_{t-1}+\frac{\beta[\theta+\omega(1-\theta)]}{\theta+\omega(1-\theta)(1+\beta)} \mathrm{E}_{t} \widehat{\pi}_{t+1} \\
& +\frac{(1-\omega)(1-\theta)(1-\beta \mu)}{\theta+\omega(1-\theta)(1+\beta)} \widehat{m c}_{t} .
\end{aligned}
$$

Equation (14) has the form of a hybrid New Keynesian Phillips curve. Notice that the pricing parameters, $\theta$ and $\omega$, affect both the lead-lag structure of inflation and the coefficient on

real marginal costs. Specifically, it is not difficult to see that an increase in $\omega$ raises the coefficient on lagged inflation and lowers the coefficients on future inflation and real marginal costs. Similarly, an increase in $\theta$ raises the coefficient on future inflation and lowers the coefficients on lagged inflation and real marginal costs. Importantly, then, inflation dynamics are informative of the extent and nature of the price rigidity and, moreover, a decline in the coefficient on real marginal costs need not imply higher menu costs (and greater price rigidity); it may, instead, imply higher information gathering/processing costs.

\section{Some interesting special cases}

It is interesting to relate the Phillips curve derived above to other specifications in the literature. If I set $\omega=0$, eliminating the pricing state in which firms index, then equation (14) collapses to

$$
\widehat{\pi}_{t}=\beta \mathrm{E}_{t} \widehat{\pi}_{t+1}+\frac{(1-\theta)(1-\beta \theta)}{\theta} \widehat{m c}_{t}
$$

which is equivalent to the purely forward-looking New Keynesian Phillips curve associated with the Calvo (1983) model, equation (1). Similarly, if I set $\theta=0$, eliminating the pricing state in which firms do not change prices, then equation (14) simplifies to

$$
\widehat{\pi}_{t}=\frac{1}{1+\beta} \widehat{\pi}_{t-1}+\frac{\beta}{1+\beta} \mathrm{E}_{t} \widehat{\pi}_{t+1}+\frac{(1-\omega)(1-\beta \omega)}{\omega(1+\beta)} \widehat{m c}_{t},
$$

which is equivalent to the Christiano, Eichenbaum, and Evans (2005) full-indexation Phillips curve.

Because equation (14) encompasses both the Calvo (1983) model and the Christiano, Eichenbaum, and Evans (2005) model, it is natural to ask whether there might also be mathematical connections between it and the Smets and Wouters (2003) partial-indexation Phillips curve, which also encompasses these two specifications. To address this question, note that, 
when approximated around a zero-inflation steady state, the partial-indexation Phillips curve is given by

$$
\widehat{\pi}_{t}=\frac{\eta}{1+\eta \beta} \widehat{\pi}_{t-1}+\frac{\beta}{1+\eta \beta} \mathrm{E}_{t} \widehat{\pi}_{t+1}+\frac{(1-\beta \xi)(1-\xi)}{(1+\eta \beta) \xi} \widehat{m c}_{t},
$$

where $\eta \in[0,1]$ represents the indexation parameter and $\xi \in(0,1)$ represents the share of firms that can optimize their prices each period. As Smets and Wouters (2003) discuss, the model that underlies equation (17) is closely related to the Calvo (1983) model, with the modification that those firms that do not optimize their prices change their prices in proportion to lagged aggregate inflation.

Proposition 1 To a first-order (log-) approximation about a zero-inflation steady state, the generalized-Calvo Phillips curve, equation (14), and the partial-indexation Phillips curve, equation (17), are isomorphic.

Proof. Define $\eta \equiv \frac{\omega(1-\theta)}{\theta+\omega(1-\theta)}$ and $\xi \equiv \mu=\theta+\omega(1-\theta)$, then the partial-indexation Phillips curve can be written as

$$
\begin{aligned}
\widehat{\pi}_{t}= & \frac{\frac{\omega(1-\theta)}{\theta+\omega(1-\theta)}}{1+\beta\left(\frac{\omega(1-\theta)}{\theta+\omega(1-\theta)}\right)} \widehat{\pi}_{t-1}+\frac{\beta}{1+\beta\left(\frac{\omega(1-\theta)}{\theta+\omega(1-\theta)}\right)} \mathrm{E}_{t} \widehat{\pi}_{t+1} \\
& +\frac{(1-\omega)(1-\theta)(1-\beta \mu)}{\left[1+\beta\left(\frac{\omega(1-\theta)}{\theta+\omega(1-\theta)}\right)\right][\theta+\omega(1-\theta)]} \widehat{m c}_{t} .
\end{aligned}
$$

After some simple cancellations, equation (18) becomes

$$
\begin{aligned}
\widehat{\pi}_{t}= & \frac{\omega(1-\theta)}{\theta+\omega(1-\theta)(1+\beta)} \widehat{\pi}_{t-1}+\frac{\beta}{\theta+\omega(1-\theta)(1+\beta)} \mathrm{E}_{t} \widehat{\pi}_{t+1} \\
& +\frac{(1-\omega)(1-\theta)(1-\beta \mu)}{\theta+\omega(1-\theta)(1+\beta)} \widehat{m c}_{t},
\end{aligned}
$$

which has the same structure as the generalized-Calvo Phillips curve. Now, by inspection, for all $\omega \in[0,1)$ and $\theta \in[0,1)$ that satisfy $\omega+\theta>0$, then $\eta \in[0,1]$ and $\xi \in(0,1)$, which establishes that the generalized-Calvo Phillips curve is a special case of the partial-indexation Phillips curve. Conversely, define $\theta \equiv \xi(1-\eta)$ and $\omega \equiv \frac{\xi \eta}{1-\xi(1-\eta)}$, which imply $\mu=\xi$, then the generalized-Calvo Phillips curve can be written as

$$
\begin{aligned}
\widehat{\pi}_{t}= & \frac{\xi \eta}{\xi(1-\eta)+\xi \eta(1+\beta)} \widehat{\pi}_{t-1}+\frac{\beta[\xi(1-\eta)+\xi \eta]}{\xi(1-\eta)+\xi \eta(1+\beta)} \mathrm{E}_{t} \widehat{\pi}_{t+1} \\
& +\frac{(1-\xi)(1-\beta \xi)}{\xi(1-\eta)+\xi \eta(1+\beta)} \widehat{m c}_{t},
\end{aligned}
$$


which in turn simplifies to

$$
\widehat{\pi}_{t}=\frac{\eta}{1+\eta \beta} \widehat{\pi}_{t-1}+\frac{\beta}{1+\eta \beta} \mathrm{E}_{t} \widehat{\pi}_{t+1}+\frac{(1-\xi)(1-\beta \xi)}{(1+\eta \beta) \xi} \widehat{m c}_{t} .
$$

Equation (19) has the same structure as the partial-indexation Phillips curve. With respect to the parameter spaces, again by inspection, for all $\eta \in[0,1]$ and $\xi \in(0,1)$, then $\omega \in[0,1)$ and $\theta \in[0,1)$ and $\theta+\omega>0$, which establishes that the partial-indexation Phillips curve is a special case of the generalized-Calvo Phillips curve. Since each specification is a special case of the other they must be isomorphic.

Proposition 1 establishes that the generalized-Calvo Phillips curve and the partial-indexation Phillips curve are mathematically equivalent, and this equivalence also has a natural intuition. The parameter $\eta$ in the partial-indexation model has as its counterpart the convolution $\frac{\omega(1-\theta)}{\theta+\omega(1-\theta)}$ in the generalized-Calvo model. To appreciate why these two parameters play the same role, observe that the numerator of $\frac{\omega(1-\theta)}{\theta+\omega(1-\theta)}$ is the share of firms that index to lagged inflation and the denominator is the share of firms that are either indexing to lagged inflation or indexing to a zero inflation rate. In terms of the contribution to inflation being made by the non-optimizing firms, the convolution $\frac{\omega(1-\theta)}{\theta+\omega(1-\theta)}$ can be thought of as the weight on lagged inflation in a weighted average of lagged inflation and zero inflation, which is naturally equivalent to the weight on lagged inflation in a model with partial indexation. Similarly, it should be clear that the term $\frac{(1-\omega)(1-\theta)}{\theta+\omega(1-\theta)}$ regulates the relationship between inflation and the optimal relative price (see equation $(8)$ ) in the same way that $\frac{(1-\xi)}{\xi}$ does in the partialindexation model and that these two expressions are equal when $\xi=\theta+\omega(1-\theta)$, which is intuitive because $\xi$ is the share of firms that do not optimize in the partial-indexation model and $\theta+\omega(1-\theta)$ is the share of firms that do not optimize in the generalized-Calvo model.

\section{System estimation}

To estimate the generalized-Calvo Phillips curve I embed it within a small-scale dynamic stochastic general equilibrium (DSGE) model and estimate the resulting system using likelihood methods. The DSGE model is standard so I present the key equations, leaving the derivations to appendices. With $c_{t}$ denoting consumption, $R_{t}$ denoting the short-term nominal interest rate, and $g_{t}$ denoting an aggregate consumption preference shock, the log-linearized consumption Euler equation is given by (see Appendix C)

$$
\widehat{c}_{t}=\frac{\gamma}{1+\gamma} \widehat{c}_{t-1}+\frac{1}{1+\gamma} \mathrm{E}_{t} \widehat{c}_{t+1}-\frac{(1-\gamma)}{\sigma}\left(R_{t}-\mathrm{E}_{t} \pi_{t+1}-\rho-g_{t}\right)
$$


where $\gamma \in(0,1)$ is the (external) habit parameter, $\sigma \in(0, \infty)$ is the coefficient of relative risk aversion, and $\rho=-\ln (\beta)$ is the discount rate. Combining the production technology, the resource constraint, and the household labor supply decision, real marginal costs are given by (see Appendix D)

$$
\widehat{m c}_{t}=\left[\chi+\frac{\sigma}{(1-\gamma)}\right] \widehat{c}_{t}-\frac{\sigma \gamma}{(1-\gamma)} \widehat{c}_{t-1}-(1+\chi) u_{t}-g_{t}
$$

where $\chi \in(0, \infty)$ is the Frisch labor supply elasticity.

With respect to the nominal interest rate, I assume that $R_{t}$ is set according to

$$
R_{t}=\left(1-\phi_{r}\right)\left[\rho+\left(1-\phi_{\pi}\right) \bar{\pi}+\phi_{\pi} \mathrm{E}_{t} \pi_{t+1}+\phi_{c} \widehat{c}_{t}\right]+\phi_{r} R_{t-1}+\epsilon_{t}
$$

which is a standard forward-looking Taylor-type rule, essentially the same as the specification studied by Clarida, Galí, and Gertler (1998, 2000). Equation (22) postulates that the central bank responds with inertia to future expected inflation and, through consumption, to the state of the business cycle. Expected future inflation rather than current or lagged inflation enters the rule to capture the fact that central banks consider the economy's future evolution when conducting monetary policy.

\subsection{Bayesian estimation}

With the parameters of model represented by $\boldsymbol{\Gamma}, p(\boldsymbol{\Gamma})$ is the prior density for $\boldsymbol{\Gamma}, p\left(\left\{\mathbf{z}_{1 t}\right\}_{2}^{T} \mid \boldsymbol{\Gamma}\right)$ is the conditional data density, and $p\left(\boldsymbol{\Gamma} \mid\left\{\mathbf{z}_{1 t}\right\}_{2}^{T}\right)$ is the posterior density of the parameter density conditional on the data and the model. As always with Bayesian estimation, interest centers on the posterior density, which from Bayes's theorem, is given by

$$
p\left(\boldsymbol{\Gamma} \mid\left\{\mathbf{z}_{t}\right\}_{2}^{T}\right)=\frac{p\left(\left\{\mathbf{z}_{t}\right\}_{2}^{T} \mid \boldsymbol{\Gamma}\right) p(\boldsymbol{\Gamma})}{p\left(\left\{\mathbf{z}_{t}\right\}_{2}^{T}\right)} .
$$

To draw from the posterior density, I use the random walk chain Metropolios-Hastings algorithm. Ten overdispersed chains of length 60,000 were constructed, from which the first 10, 000 "burn-in" draws were discarded, leaving a total of 500,000 usable draws. Convergence of the chains was determined using diagnostics developed by Gelman (1995) and Geweke (1992).

To calculate the marginal data density, or marginal likelihood,

$$
p\left(\left\{z_{t}\right\}_{2}^{T}\right)=\int_{\boldsymbol{\Gamma}} p\left(\left\{z_{t}\right\}_{2}^{T} \mid \boldsymbol{\Gamma}\right) p(\boldsymbol{\Gamma}) d \boldsymbol{\Gamma}
$$


which is the probability of observing the data given the model, I use Geweke's (1999) modification of the Gelfand and Dey (1994) method. As equation (24) shows, the marginal likelihood is evaluated by averaging the conditional data density with respect to the prior density.

\subsection{Data}

To estimate the model, I use U. S. data spanning the period 1982:1 - 2007:2, which excludes the period of nonborrowed reserves targeting that occurred in the early 1980s and the recession that began in late-2007 associated with the collapse in the U. S. housing market, but otherwise reflects the time during which Paul Volcker, Alan Greenspan, and Ben Bernanke were Federal Reserve chairmen. I use the quarterly average of the federal funds rate to measure $R_{t}$, use $100 \times \ln \left(C_{t} / C_{t}^{T}\right)$ to measure the consumption gap, where $C_{t}$ is real consumption and $C_{t}^{T}$ is trend consumption, ${ }^{7}$ and use $400 \times \ln \left(P_{t} / P_{t-1}\right)$, where $P_{t}$ is the personal consumption expenditure (PCE) price index, to measure inflation.

\subsection{Priors}

Aside from the parameters describing the shock processes, the key model parameters are $\boldsymbol{\Gamma}=$ $\left\{\chi, \rho, \gamma, \sigma, \chi, \theta, \omega, \bar{\pi}, \phi_{\pi}, \phi_{c}, \phi_{r}\right\}$. The priors for these behavioral parameters are summarized in Table $2 \mathrm{a}$.

\begin{tabular}{c|c|c|c|c}
\hline \hline \multicolumn{5}{c}{ Table 2a: Priors for Structural Parameters } \\
\hline Parameter & Distribution & Mean & Std Dev. & $90 \%$ Interval \\
\hline$\rho$ & Normal & 2.50 & 0.50 & {$[1.68,3.32]$} \\
$\gamma$ & Beta & 0.75 & 0.10 & {$[0.57,0.90]$} \\
$\sigma$ & Gamma & 2.00 & 2.00 & {$[0.10,5.99]$} \\
$\chi$ & Normal & 2.00 & 0.75 & {$[0.76,3.23]$} \\
$\theta$ & Beta & 0.66 & 0.20 & {$[0.49,0.82]$} \\
$\omega$ & Uniform & 0.50 & 0.29 & {$[0.05,0.95]$} \\
$\bar{\pi}$ & Normal & 3.00 & 0.50 & {$[2.18,3.82]$} \\
$\phi_{\pi}$ & Normal & 1.50 & 0.20 & {$[1.17,1.83]$} \\
$\phi_{c}$ & Normal & 1.00 & 0.20 & {$[0.67,1.33]$} \\
$\phi_{r}$ & Beta & 0.75 & 0.10 & {$[0.57,0.90]$} \\
\hline \hline
\end{tabular}

Briefly, the priors for $\rho$ and $\bar{\pi}$ have means equaling 2.50 and 3.00 percent, respectively, at annual rates. The priors for $\gamma$ and $\phi_{r}$ are each Beta distributions with means equaling 0.75. The prior for the inflation indexation parameter, $\omega$, is a uniform distribution over the unit interval while that for the frequency of price adjustment, $\theta$, reflecting the results in Nakamura and Steinsson (2008), has a Beta distribution that is centered on 0.66. The prior for the

\footnotetext{
${ }^{7}$ Trend consumption was constructed using the Hodrick-Prescott filter with $\lambda=1,600$.
} 
coefficient of relative risk aversion, $\sigma$, has a Gamma distribution with a mean equaling 2.00 and, to reflect the wide range of estimates in the literature, a relatively large standard deviation of 2.00. Based on Smets and Wouters (2007), the prior for the labor-supply elasticity, $\chi$, has a Normal distribution with a mean equaling 2.00 and a standard deviation of 0.75 .

The prior for the shock process is implemented as follows. First, the solution to the rational expectations model is written in the form

$$
\mathbf{z}_{t}=\mathbf{h}+\mathbf{H} \mathbf{z}_{t-1}+\boldsymbol{\varepsilon}_{t}
$$

where $\varepsilon_{t}=\mathbf{G v}_{t}$ are reduced-form shocks. The priors for the elements in $\boldsymbol{\Sigma}=\mathrm{E}\left[\varepsilon_{t} \varepsilon_{t}^{\prime}\right]$ are summarized in Table 2b.

\begin{tabular}{c|c|c|c|c}
\hline \hline \multicolumn{5}{c}{ Table 2b: Priors for Reduced-Form Shocks } \\
\hline Parameter & Distribution & Mean & Std Dev. & $90 \%$ Interval \\
\hline$\sigma_{1}$ & Inverted Gamma & 1.00 & 0.20 & {$[0.72,1.36]$} \\
$\sigma_{2}$ & Inverted Gamma & 0.50 & 0.20 & {$[0.27,0.87]$} \\
$\sigma_{3}$ & Inverted Gamma & 0.70 & 0.20 & {$[0.44,1.07]$} \\
$\operatorname{cov}\left(\varepsilon_{1} \varepsilon_{2}\right)$ & Normal & 0.00 & 0.20 & {$[-0.33,0.33]$} \\
$\operatorname{cov}\left(\varepsilon_{1} \varepsilon_{3}\right)$ & Normal & 0.00 & 0.20 & {$[-0.33,0.33]$} \\
$\operatorname{cov}\left(\varepsilon_{2} \varepsilon_{3}\right)$ & Normal & 0.00 & 0.20 & {$[-0.33,0.33]$} \\
\hline \hline
\end{tabular}

\subsection{DSGE model estimates}

Table 3 presents the estimates of the DSGE model parameters. The table displays the posterior mean, median, and mode, and a 90 percent probability interval for the Bayesian estimation. Also shown is the (log-) marginal likelihood (log-ML).

\begin{tabular}{c|c|c|c|c}
\hline \hline \multicolumn{5}{c}{ Table 3: Bayesian Estimates of the generalized-Calvo Model } \\
\hline Parameter & Post. Mean & Post. Median & Post. Mode & $90 \%$ Interval \\
\hline$\rho$ & 2.566 & 2.569 & 2.601 & {$[1.982,3.141]$} \\
$\gamma$ & 0.886 & 0.887 & 0.895 & {$[0.823,0.940]$} \\
$\sigma$ & 7.252 & 6.722 & 5.443 & {$[2.979,13.23]$} \\
$\chi$ & 2.086 & 2.078 & 2.085 & {$[0.881,3.301]$} \\
$\theta$ & 0.397 & 0.396 & 0.399 & {$[0.259,0.539]$} \\
$\omega$ & 0.964 & 0.965 & 0.967 & {$[0.941,0.981]$} \\
$\bar{\pi}$ & 3.270 & 3.256 & 3.329 & {$[2.743,3.844]$} \\
$\phi_{\pi}$ & 1.634 & 1.628 & 1.634 & {$[1.355,1.934]$} \\
$\phi_{c}$ & 1.079 & 1.080 & 1.083 & {$[0.773,1.386]$} \\
$\phi_{r}$ & 0.871 & 0.872 & 0.872 & {$[0.839,0.902]$} \\
\hline $\log -M L$ & \multicolumn{4}{|c}{-324.655} \\
\hline \hline
\end{tabular}

The Bayesian estimates of the rate of time preference, $\rho$, are about 2.6. This estimate is consistent with those of the equilibrium real interest rate (Laubach and Williams, 2003) 
and place the quarterly discount factor at just over 0.99 , in line with values widely used in calibration exercises. Looking at the utility function parameters, the habit formation parameter, $\gamma$, is estimated to be about 0.89 , implying that habit formation is important and that there is considerable inertia in consumption. Elsewhere, estimates of $\gamma$ vary widely. Smets and Wouters (2005) estimate $\gamma=0.69$, Smets and Wouters (2007) estimate $\gamma=0.71$, Altig, Christiano, Eichenbaum, and Linde (2004) estimate $\gamma=0.65$, Giannoni and Woodford (2003) estimate $\gamma=1.00$, while the results in Smets (2003) and Cho and Moreno (2005) imply that $\gamma$ equals 0.79 and 1.00, respectively. Calibration exercises often set $\gamma$ to 0.80 (McCallum and Nelson, 1999). Turning to $\sigma$, estimates in the literature are also wide-ranging. The Bayesian estimation returns a posterior median for $\sigma$ that is about 6.7. Elsewhere, Fuhrer (2000) obtains $\sigma=6.11$ while Kim (2000) obtains $\sigma=14.22$. Using Bayesian methods, Smets and Wouters (2005) get $\sigma=1.62$ for the posterior median, while Levin, Onatski, Williams, and Williams (2006) report $\sigma=2.19$ for the posterior mean. At the other end of the spectrum, Rotemberg and Woodford (1997) estimate $\sigma=0.16$, Amato and Laubach (2003) estimate $\sigma=0.26$, and Giannoni and Woodford (2003) estimate $\sigma=0.75$. The posterior mean of the labor supply elasticity, $\chi$, is about 2.1, which compares to the value 1.83 estimated by Smets and Wouters (2007) and the value 1.49 estimated by Levin, Onatski, Williams, and Williams (2006). Based on their reading of micro-data, Chang and Kim (2005) argue that $\chi$ should be greater than 2.0 and set $\chi$, in their model, to 2.5.

Regarding the policy-rule parameters, the Bayesian estimates place the implicit inflation target at around 3.3 percent. These estimates of $\bar{\pi}$ are very similar to those obtained by Clarida, Galí, and Gertler (2000), while being slightly higher than that obtained by Favero and Rovelli (2003), who estimate $\bar{\pi}$ to be 2.63 percent. I estimate the coefficient on expected future inflation to be about 1.6, the coefficient on the consumption gap to be about 1.1, and the coefficient on lagged interest rates to be about 0.85 . These coefficients are all consistent with other estimated Taylor-type rules (see Clarida, Galí, and Gertler (2000) and Dennis $(2006,2009))$; they indicate an activist, but inertial, approach to monetary policy and rule out sunspot behavior.

With respect to pricing behavior, the two key parameters are $\theta$ and $\omega$. The Bayesian estimation has the distribution for $\theta$ centered on about 0.40 , with a 90 percent probability interval covering 0.26 to 0.54 . These estimates place the frequency of price adjustment somewhere around 0.60, suggesting relatively frequent price adjustment and that menu costs are perhaps not a huge impediment to a firm changing its price. At the same time, the estimate 
of $\omega$ is large, implying that most firms that change prices do so using indexation. Together, the estimates of $\theta$ and $\omega$ are consistent with the view that information gathering/processing costs are more important for pricing behavior than menu costs.

\subsection{Partial-indexation Phillips curve estimates}

Proposition 1 shows how estimates of the partial-indexation Phillips curve can be used to shed light on the values of $\theta$ and $\omega$ in the generalized-Calvo Phillips curve; a range of estimates for the U.S are reported in Table $4 .^{8}$

\begin{tabular}{c|c|c|c|c|c|c}
\hline \hline \multicolumn{7}{c}{ Table 4: Estimates of $\theta$ and $\omega$ from the Partial-Indexation Phillips Curve } \\
\hline Study & Estimator & Sample & $\xi$ & $\eta$ & $\theta$ & $\omega$ \\
\hline Sahuc (2004) & GMM & $1970: 1-2002: 4$ & 0.87 & 0.68 & 0.28 & 0.82 \\
Smets and Wouters (2005) & Bayesian & $1974: 1-2002: 2$ & 0.87 & 0.66 & 0.30 & 0.82 \\
Rabanal and Rubio-Ramírez (2005) & Bayesian & $1960: 1-2001: 4$ & 0.90 & 0.76 & 0.22 & 0.87 \\
Jondeau and Le Bihan (2005) & GMM & $1970: 1-1999: 4$ & 0.88 & 0.46 & 0.47 & 0.77 \\
Smets and Wouters (2007) & Bayesian & $1966: 1-2004: 4$ & 0.76 & 0.24 & 0.58 & 0.43 \\
Del Negro and Schorfheide (2008) & Bayesian & $1982: 4-2005: 4$ & 0.78 & 0.19 & 0.63 & 0.40 \\
Dennis (2009) & FIML & $1983: 1-2004: 2$ & 0.88 & 0.69 & 0.27 & 0.83 \\
\hline \hline
\end{tabular}

The key result that emerges from Table 4 is that estimates of $\theta$ and $\omega$ inferred from estimates of the partial-indexation Phillips curve are relatively consistent with those for the generalized-Calvo model shown in Table 3, even though they are obtained from DSGE models that are quite different from the one I estimate. Specifically, the estimates of $\theta$ in Table 4 are spanned by the interval $0.22-0.63$, and generally reflect quite rapid price adjustment. Similarly, other than those obtained by Smets and Wouters (2007) and Del Negro and Schorfheide (2008), the estimates of $\omega$ in Table 4 indicate that the share of firms that index prices is large.

\section{Alternative pricing specifications}

In this section I estimate three additional Phillips curve specifications and consider the results in light of the generalized-Calvo model estimated above. With the remainder of the model continuing to be given by equations (20) - (22), I estimate the New Keynesian Phillips curve, equation (15), the full-indexation Phillips curve, equation (16), and a hybrid Phillips curve

\footnotetext{
${ }^{8}$ As earlier, where necessary, the estimates in Table 4 have been made consistent with a Cobb-Douglas production technology and rental markets for capital and labor.
} 
developed by Galí and Gertler (1999), which is given by

$$
\begin{aligned}
\pi_{t}= & \frac{\omega}{\theta+\omega[1-\theta(1-\beta)]} \pi_{t-1}+\frac{\beta \theta}{\theta+\omega[1-\theta(1-\beta)]} \mathrm{E}_{t} \pi_{t+1} \\
& +\frac{(1-\omega)(1-\theta)(1-\beta \theta)}{\theta+\omega[1-\theta(1-\beta)]} \widehat{m c}_{t} .
\end{aligned}
$$

Although $\theta$ and $\omega$ carry the same interpretation in the Galí and Gertler (1999) model as they do in the generalized-Calvo model, the firm's optimization problem is quite different. Thus, while similar in the variables it depends upon, equation (26) is otherwise quite dissimilar to the generalized-Calvo Phillips curve, equation (14).

Table 5 presents median estimates of the parameters in the three alternative pricing specifications discussed above. ${ }^{9}$ As noted previously, these alternative pricing specifications are estimated jointly with equations (20)-(22).

\begin{tabular}{c|c|c|c}
\hline \hline \multicolumn{3}{c}{ Table 5: Bayesian Estimates of Alternative Pricing Specifications } \\
\hline Parameter & Calvo & Full Indexation & Galí-Gertler \\
\hline$\rho$ & 2.536 & 2.511 & 2.583 \\
$\gamma$ & 0.889 & 0.885 & 0.888 \\
$\sigma$ & 8.219 & 6.118 & 6.008 \\
$\chi$ & 2.025 & 2.164 & 2.060 \\
$\theta$ & 0.973 & - & 0.960 \\
$\omega$ & - & 0.961 & 0.629 \\
$\bar{\pi}$ & 3.491 & 3.064 & 3.180 \\
$\phi_{\pi}$ & 1.621 & 1.620 & 1.620 \\
$\phi_{c}$ & 1.047 & 1.085 & 1.090 \\
$\phi_{r}$ & 0.867 & 0.864 & 0.868 \\
\hline $\log -M L$ & -343.985 & -329.167 & -326.579 \\
\hline \hline
\end{tabular}

Setting the estimates of $\theta$ and $\omega$ aside for the moment, the estimates of the remaining structural parameters are all reasonably consistent across the three specifications and consistent with those reported in Table 3. With respect to the two pricing parameters, estimates from the Calvo model, the full-indexation model, and the Galí-Gertler model all suggest that the share of firms that set their price optimally each quarter is small. However, where the Calvo model suggests that the majority of firms keeps their prices unchanged, the fullindexation model suggests that the same majority index their prices to lagged inflation. The Galí-Gertler model suggests that while the majority of firms keeps their prices unchanged each period, about 63 percent of those that do change their prices do so by rule of thumb.

\footnotetext{
${ }^{9}$ For the model containing the partial-indexation Phillips curve, the prior for $\xi$ and $\eta$ was a Beta distribution with mean of 0.5 and standard deviation of 0.2 . The prior for the remaining parameters was the same as that reported in Tables $2 \mathrm{a}$ and $2 \mathrm{~b}$.
} 
Clearly, although the Galí-Gertler model and the generalized-Calvo model both highlight the importance of rule-of-thumb pricing or price indexation for inflation dynamics, they tell very different stories regarding the frequency of price adjustment. Specifically, the Galí-Gertler model indicates that more than 90 percent of firms keep their price unchanged each quarter whereas the generalized-Calvo model places this share at closer to 40 percent.

\section{Conclusion}

The Calvo-based New Keynesian Phillips curve has been widely criticized for being economically implausible, for being inconsistent with micro-data on the frequency of price adjustment, and for being unable to account for the persistence in inflation. Popular alternatives, such as the full-indexation model and the partial-indexation model, are much better able to explain the persistence in inflation, but, because they assume that all prices change every period, they too are unable to match micro-evidence on the frequency of price changes. These criticisms are important because New Keynesian business cycle models are increasingly used to study issues such as how monetary policy should be conducted to maximize welfare, and the nature of these policies hinge critically on precisely how and why prices are rigid. More generally, they challenge whether the leading New Keynesian models of price adjustment provide a useful and economically sensible description of inflation dynamics. Against this background, the main contribution of this paper is to present a pricing model that can usefully speak to these criticisms.

After outlining the generalized-Calvo pricing model, I derive its Phillips curve and relate it to other specifications in the literature. Specifically, I prove that it encompasses the Calvo Phillips curve, the full-indexation Phillips curve, and the partial-indexation Phillips curve. This encompassing result, together with the fact that the full- and the partialindexation models counterfactually force all firms to change their prices every period, makes the generalized-Calvo Phillips curve particularly attractive for empirical applications. Taking this as motivation, I build a small-scale New Keynesian business cycle model and estimate versions of it on U.S. macroeconomic data.

The main empirical results are as follows. First, the estimates of the generalized-Calvo model place the quarterly frequency of price adjustment at about 0.6. In this respect, the generalized-Calvo model, unlike many other time-contingent pricing models, reveals a relatively high frequency of price adjustment. Second, with around 60 percent of firms changing their prices each quarter and with the majority of these price-changing firms resorting to in- 
dexation, the model estimates are consistent with the view that menu costs are a much less important factor for price setting than information gathering/processing costs.

\section{A Appendix: Aggregate prices}

From the Dixit-Stiglitz aggregator, the price level is defined according to

$$
P_{t} \equiv\left[\int_{0}^{1} P_{t}(i)^{1-\varepsilon} d i\right]^{\frac{1}{1-\varepsilon}}
$$

Recognizing that at any point in time firms either set their price optimally, use price indexation, or keep their price unchanged, equation (A1) is equivalent to

$$
P_{t}^{1-\varepsilon}=(1-\omega)(1-\theta) P_{t}^{* 1-\varepsilon}+\left(1+\pi_{t-1}\right)^{1-\varepsilon} \int_{\theta}^{\theta+\omega(1-\theta)} P_{t-1}(i)^{1-\varepsilon} d i+\int_{0}^{\theta} P_{t-1}(i)^{1-\varepsilon} d i .
$$

Because the firms that do not change their prices and that use indexation are chosen randomly, equation (A2) is equivalent to

$$
\begin{aligned}
P_{t}^{1-\varepsilon}= & (1-\omega)(1-\theta) P_{t}^{* 1-\varepsilon}+\left(1+\pi_{t-1}\right)^{1-\varepsilon} \omega(1-\theta) \int_{0}^{1} P_{t-1}(i)^{1-\varepsilon} d i \\
& +\theta \int_{0}^{1} P_{t-1}(i)^{1-\varepsilon} d i \\
= & (1-\omega)(1-\theta) P_{t}^{* 1-\varepsilon}+\omega(1-\theta)\left(1+\pi_{t-1}\right)^{1-\varepsilon} P_{t-1}^{1-\varepsilon}+\theta P_{t-1}^{1-\varepsilon} .
\end{aligned}
$$

Finally, equation (A3) implies

$$
P_{t}=\left[(1-\omega)(1-\theta) P_{t}^{* 1-\varepsilon}+\omega(1-\theta)\left(1+\pi_{t-1}\right)^{1-\varepsilon} P_{t-1}^{1-\varepsilon}+\theta P_{t-1}^{1-\varepsilon}\right]^{\frac{1}{1-\varepsilon}}
$$

which is equation (7) in the text. If I assume, say, that there exists an initial period in which there is no relative price dispersion, then it is straightforward to see that equation (A4) holds for all $t \geq 1$.

Alternatively, by accounting for how firms that either did not change prices today or that used price indexation today have set prices in the past, and exploiting, first, that a firm's pricing strategy is determined randomly, and, second, that as the initial period tends to $-\infty$ the share of firms setting prices today that have never set their prices optimally converges to zero (or that there exists an initial period in which there is no relative price dispersion, making the summation in equation (A5) finite), equation (A2) can be written as

$$
P_{t}^{1-\varepsilon}=(1-\omega)(1-\theta) \sum_{k=0}^{\infty}\left(\prod_{l=1}^{k}\left[\theta+\omega(1-\theta)\left(1+\pi_{t+l-1}\right)\right]\right) P_{t}^{* 1-\varepsilon}
$$

which, under these assumptions, is convergent for all $\omega \in[0,1)$ and $\theta \in[0,1)$. From equation (A5), it follows that $P_{t-1}^{1-\varepsilon}$ is given by

$$
P_{t-1}^{1-\varepsilon}=(1-\omega)(1-\theta) \sum_{k=0}^{\infty}\left(\prod_{l=1}^{k}\left[\theta+\omega(1-\theta)\left(1+\pi_{t+l-1}\right)^{1-\varepsilon}\right]\right) P_{t-1}^{* 1-\varepsilon},
$$


and combining equations (A5) and (A6) yields

$$
P_{t}^{1-\varepsilon}-\left[\theta+\omega(1-\theta)\left(1+\pi_{t+l-1}\right)^{1-\varepsilon}\right] P_{t-1}^{1-\varepsilon}=(1-\omega)(1-\theta) P_{t}^{* 1-\varepsilon},
$$

which implies

$$
\begin{aligned}
P_{t}^{1-\varepsilon} & =(1-\omega)(1-\theta) P_{t}^{* 1-\varepsilon}+\left[\theta+\omega(1-\theta)\left(1+\pi_{t+l-1}\right)^{1-\varepsilon}\right] P_{t-1}^{1-\varepsilon}, \\
& =(1-\omega)(1-\theta) P_{t}^{* 1-\varepsilon}+\omega(1-\theta)\left(1+\pi_{t+l-1}\right)^{1-\varepsilon} P_{t-1}^{1-\varepsilon}+\theta P_{t-1}^{1-\varepsilon},
\end{aligned}
$$

leading to

$$
P_{t}=\left[(1-\omega)(1-\theta) P_{t}^{* 1-\varepsilon}+\omega(1-\theta)\left(1+\pi_{t+l-1}\right)^{1-\varepsilon} P_{t-1}^{1-\varepsilon}+\theta P_{t-1}^{1-\varepsilon}\right]^{\frac{1}{1-\varepsilon}},
$$

which, again, is equation (7) in the text.

\section{B Appendix: The non-zero-inflation steady state case}

Let $\bar{\pi} \in(-1, \tilde{\pi}]$ denote the inflation rate in the nonstochastic steady state. With $p_{t}^{*}=\frac{P_{t}^{*}}{P_{t}}$ representing the optimal relative price, it follows from equation (A4) (equation (7) in the text) that in a non-zero-inflation steady state, the steady state optimal relative price, $\bar{p}^{*}$, is given by

$$
\bar{p}^{*}=\left[\frac{1-\omega(1-\theta)-\theta(1+\bar{\pi})^{\varepsilon-1}}{(1-\omega)(1-\theta)}\right]^{\frac{1}{1-\varepsilon}} .
$$

In order for the steady state optimal relative price to be positive $\left(\bar{p}^{*}>0\right)$, it must be the case that

$$
1-\omega(1-\theta)-\theta(1+\bar{\pi})^{\varepsilon-1}>0,
$$

which, for $\theta \in(0,1)$, leads to

$$
\widetilde{\pi}_{1}<\left[\left(\frac{1-\omega(1-\theta)}{\theta}\right)^{\left(\frac{1}{\varepsilon-1}\right)}-1\right] .
$$

Equation (B1) implies that $\bar{p}^{*}$ is increasing in $\bar{\pi}$ for $\bar{\pi} \in\left(-1, \widetilde{\pi}_{1}\right]$, and greater than one for $\bar{\pi} \in\left(0, \widetilde{\pi}_{1}\right]$, less than one for $\bar{\pi} \in(-1,0)$, and equal to one for $\bar{\pi}=0$. Notably, because prices are not fully flexible, on occasions when they can change prices, firms respond to a positive steady state inflation rate by raising prices by more than they otherwise would have, with inflation then eroding these high relative prices over time. Of course, the extent to which a positive steady state inflation rate lifts the steady state optimal relative price is mitigated by greater substitutability between goods and by greater price flexibility. Now, looking at equation (B2), it is straightforward to see that $\widetilde{\pi}_{1}$ is decreasing in $\varepsilon$, which is intuitive because greater substitutability between goods is incompatible with sticky prices unless steady state inflation is low. Similarly, for a given elasticity of substitution between goods, greater price rigidity requires a lower steady state inflation rate if the optimal relative price is to remain well-defined.

Log-linearizing equation (A4) around a non-zero-inflation steady state, the quasi-difference in aggregate inflation is related to the optimal relative price according to

$$
\begin{aligned}
\pi_{t}-\bar{\pi}= & \frac{\omega(1-\theta)}{\omega(1-\theta)+\theta(1+\bar{\pi})^{\varepsilon-1}}\left(\pi_{t-1}-\bar{\pi}\right) \\
& +(1+\bar{\pi})\left(\frac{1-\omega(1-\theta)-\theta(1+\bar{\pi})^{\varepsilon-1}}{\omega(1-\theta)+\theta(1+\bar{\pi})^{\varepsilon-1}}\right) \widehat{p}_{t}^{*}
\end{aligned}
$$


where $\widehat{p}_{t}^{*}$ denotes the percent deviation in $p_{t}^{*}$ from $\bar{p}^{*}$. Equation (B3) is the analogue of equation (8) in the text.

From equation (11), the pricing decision for firms that can set their price optimally leads to the first-order condition

$$
\mathrm{E}_{t} \sum_{j=0}^{\infty}(\beta \mu)^{j} \frac{\lambda_{t+j}}{\lambda_{t}} y_{t+j}(i)\left[\frac{p_{t}^{*}(i)\left(\prod_{k=1}^{j} S_{t+k}\right)}{\prod_{k=1}^{j}\left(1+\pi_{t+k}\right)}-\frac{\epsilon}{(\epsilon-1)} m c_{t+j}\right]=0,
$$

which, provided $\beta \mu(1+\bar{\pi})<1$, implies that the steady state relationship between real marginal costs and the optimal relative price is

$$
\overline{m c}=\frac{\varepsilon-1}{\varepsilon}\left(\frac{\omega(1-\theta)}{\theta+\omega(1-\theta)}+\frac{\theta}{\theta+\omega(1-\theta)} \frac{1-\beta \mu(1+\bar{\pi})}{1-\beta \mu}\right) \bar{p}^{*} .
$$

Equation (B5) reveals the steady state markup over real marginal costs as a function of the model's parameters. In a zero-inflation steady state, the markup depends only on the elasticity of substitution between goods and is given by $\frac{1}{\varepsilon-1}$. More generally, equation (B5) shows that in a non-zero-inflation steady state the markup depends on $\beta, \theta, \omega$, and $\bar{\pi}$, in addition to $\varepsilon$. Although the steady state markup continues to be an increasing function of $\varepsilon$, it is also an increasing function of the steady state inflation rate.

The restriction that the parameters satisfy $\beta \mu(1+\bar{\pi})<1$, which is needed to ensure that the model has a well-defined steady state, gives rise to the condition

$$
\tilde{\pi}_{2}<\left(\frac{1}{\beta \mu}\right)-1
$$

indicating that $\tilde{\pi}_{2}$ is declining in the discount factor, $\beta$, and in the share of non-optimizing firms, $\mu$. Combining equations (B2) and (B6), $\tilde{\pi}$ is given by

$$
\tilde{\pi}=\min \left\{\tilde{\pi}_{1}, \tilde{\pi}_{2}\right\} .
$$

Log-linearizing equation (B4) around a non-zero-inflation steady state and assuming symmetry yields

$$
\begin{aligned}
\left(\frac{\theta}{1-\beta \mu}+\frac{\omega(1-\theta)}{1-\beta \mu(1+\bar{\pi})}\right) \widehat{p}_{t}^{*}= & \left(\frac{\theta}{1-\beta \mu}+\frac{\omega(1-\theta)}{1-\beta \mu(1+\bar{\pi})}\right) \beta \mu(1+\bar{\pi}) \mathrm{E}_{t} \widehat{p}_{t+1}^{*} \\
& +\left(\frac{\theta}{1-\beta \mu}+\frac{\omega(1-\theta)}{1-\beta \mu(1+\bar{\pi})}\right) \beta \mu \mathrm{E}_{t}\left(\pi_{t+1}-\bar{\pi}\right) \\
& +\left(\frac{\theta(1-\beta \mu(1+\bar{\pi}))}{1-\beta \mu}+\omega(1-\theta)\right) \widehat{m c}_{t} \\
& -\frac{\omega(1-\theta) \beta \mu}{1-\beta \mu(1+\bar{\pi})}\left(\pi_{t}-\bar{\pi}\right),
\end{aligned}
$$

which is the analogue of equation (13) in the text.

The Phillips curve associated with this pricing structure can be obtained by combining equations (B3) and (B7) in the usual way. Although the coefficients in the resulting expression are complicated functions of the model parameters, in terms of its general structure, the generalized-Calvo Phillips curve is given by

$$
\pi_{t}-\bar{\pi}=f(\theta, \omega, \varepsilon, \beta, \bar{\pi}) \mathrm{E}_{t}\left(\pi_{t+1}-\bar{\pi}\right)+b(\theta, \omega, \varepsilon, \beta, \bar{\pi})\left(\pi_{t-1}-\bar{\pi}\right)+s(\theta, \omega, \varepsilon, \beta, \bar{\pi}) \widehat{m c}_{t},
$$


containing both forward- and backward-looking inflation dynamics and having real marginal costs as the driving variable. The relationship between the Phillips curve coefficients, $f, b$, and $s$, and the model parameters is complicated but straightforward to analyze numerically.

To this end, with $\beta$ fixed at 0.99 , the four panels in Figure 2 illustrate how $f, b$, and $s$ vary in response to changes in $\theta, \omega, \varepsilon$, and $\bar{\pi}$. For this exercise, I set $\theta=0.50, \omega=0.50, \varepsilon=11$, and $\bar{\pi}=0.005$ and consider independent variations in each parameter holding the remaining parameters unchanged.

A: Response of Phillips Curve Coefficients to Varying $\Theta$

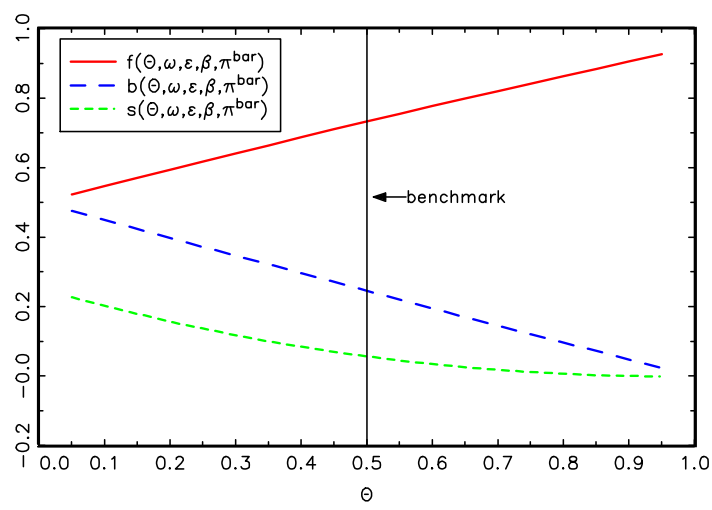

C: Response of Phillips Curve Coefficients to Varying $\varepsilon$

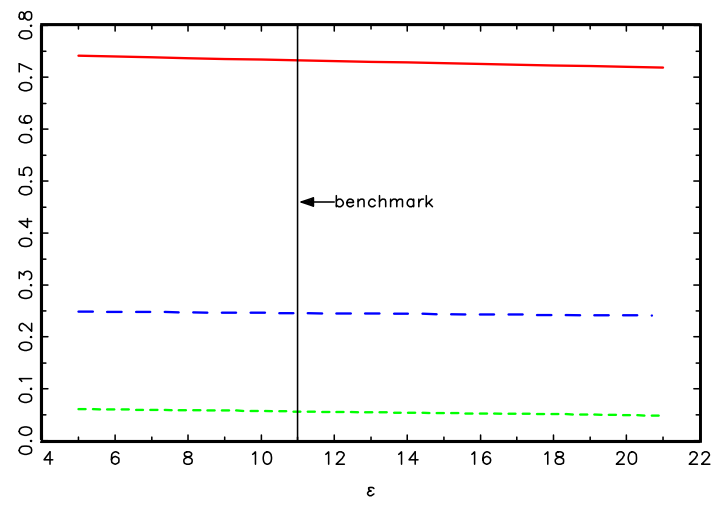

B: Response of Phillips Curve Coefficients to Varying $\omega$

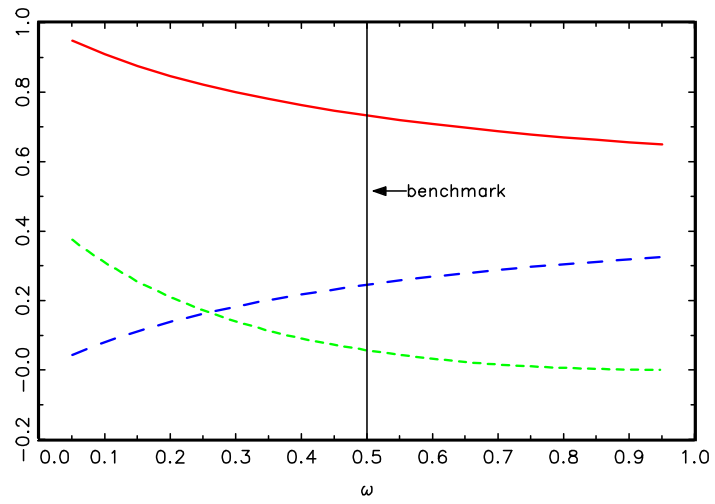

D: Response of Phillips Curve Coefficients to Varying $\pi^{\text {bar }}$

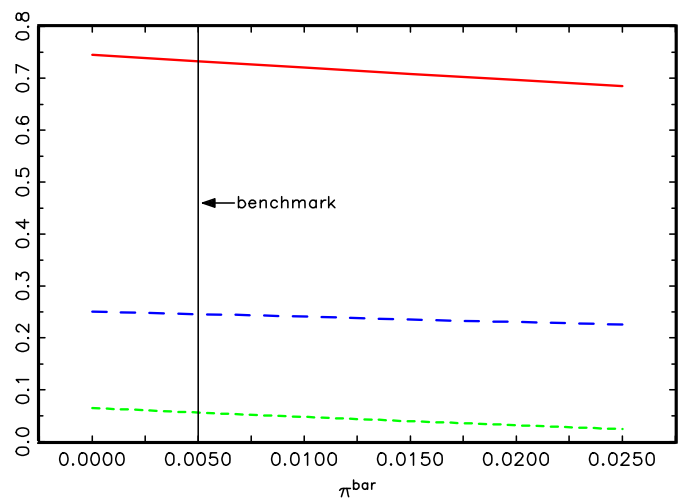

Figure 2: Sensitivity analysis

Figure 2 reveals two important results. First, the model coefficients are sensitive to variation in $\theta$ and $\omega$, which implies that the Phillips curve is informative for these two pricing parameters. Second, the model coefficients are not especially sensitive to variation in $\varepsilon$ and $\bar{\pi}$, which implies that estimates of $\theta$ and $\omega$ are likely to be robust to different assumptions regarding $\varepsilon$ and $\bar{\pi}$.

\section{Appendix: The household problem}

Households choose consumption, $c_{t}$, investment, $i_{t}$, their supply of labor, $l_{t}$, and their holdings of nominal money balances, $m_{t}$, and bonds, $b_{t}$, to maximize

$$
\mathrm{E}_{t} \sum_{j=0}^{\infty} \beta^{j}\left[\frac{e^{g_{t}}\left(c_{t+j}-\gamma C_{t+j-1}\right)^{1-\sigma}}{1-\sigma}+\frac{\left(\frac{m_{t+j}}{P_{t+j}}\right)^{1-\alpha}}{1-\alpha}-\frac{l_{t+j}^{1+\chi}}{1+\chi}\right],
$$


where $\{\sigma, \alpha, \chi\} \in(0, \infty)$, where $\gamma \in[0,1)$, and where $g_{t}, g_{t} \sim$ i.i.d. $\left[0, \sigma_{g}^{2}\right]$, is an aggregate consumption-preference shock, subject to the budget constraint

$$
c_{t}+\frac{m_{t}}{P_{t}}+\frac{b_{t}}{P_{t}}+i_{t}=w_{t} l_{t}+r_{t} k_{t}+\frac{\left(1+R_{t-1}\right)}{P_{t}} b_{t-1}+\frac{m_{t-1}}{P_{t}}+\frac{\Pi_{t}}{P_{t}}
$$

and the capital accumulation equation

$$
k_{t+1}=(1-\delta) k_{t}+i_{t},
$$

where $R_{t}$ denotes the nominal interest rate, $w_{t}$ denotes the consumption real wage, $r_{t}$ denotes the real rental payment on capital, $\Pi_{t}$ denotes the lump-sum profits households earn from dividend payments from firms and the seigniorage revenues households receive from the government, and $k_{t}$ denotes the capital stock owned by the household. Equation (C1) allows for habit formation, positing that what matters for households is their consumption in relation to lagged aggregate consumption, $C_{t-1}$.

Since household consumption must always remain above the habit stock $\left(c_{t}-\gamma C_{t-1}\right)>0$, additive habits are closely related to the notion that there is a subsistence level below which a household's consumption cannot fall. The first-order conditions for the Lagrangian, $\Lambda$, associated with the household's problem, include

$$
\begin{aligned}
\frac{\partial \Lambda}{\partial c_{t}} & : \quad e^{g_{t}}\left(c_{t}-\gamma C_{t-1}\right)^{-\sigma}-\lambda_{t}=0 \\
\frac{\partial \Lambda}{\partial l_{t}} & : \quad \lambda_{t} w_{t}-l_{t}^{\chi}=0 \\
\frac{\partial \Lambda}{\partial b_{t}} & : \beta\left(1+R_{t}\right) \mathrm{E}_{t}\left[\left(\frac{P_{t}}{P_{t+1}}\right) \lambda_{t+1}\right]-\lambda_{t}=0 \\
\frac{\partial \Lambda}{\partial k_{t+1}} & : \quad \beta \mathrm{E}_{t}\left[\left(r_{t+1}+1-\delta\right) \lambda_{t+1}\right]-\lambda_{t}=0 .
\end{aligned}
$$

Equation (C2) simply defines $\lambda_{t}$, the shadow price of capital, to equal the marginal utility of consumption. Equation (C3) implies that households supply labor up to the point where the marginal rate of substitution between consumption and leisure equals the consumption real wage, $w_{t}$. Equation (C4) shows that the bond market clears at an aggregate stock of zero when the expected change in the shadow price of capital equals the ex ante real interest rate. Finally, equations (C5) and (C4) imply that in equilibrium households are indifferent between owning bonds and capital.

Combining equations $(\mathrm{C} 2)$ and $(\mathrm{C} 4)$, the log-linear consumption Euler equation is

$$
\widehat{c}_{t}=\frac{\gamma}{1+\gamma} \widehat{c}_{t-1}+\frac{1}{1+\gamma} E_{t} \widehat{c}_{t+1}-\frac{(1-\gamma)}{\sigma}\left(R_{t}-\mathrm{E}_{t} \pi_{t+1}-\rho-g_{t}\right),
$$

which is equivalent to equation (20) in the text.

\section{Appendix: Aggregate real marginal costs}

Cost minimization implies that firms rent capital and labor such that

$$
\frac{W_{t}}{P_{t}}=m c_{t}(i) \frac{\kappa y_{t}(i)}{l_{t}(i)},
$$


implying that a firms' real marginal costs depend on the ratio of the consumption real wage to its marginal productivity of labor, i.e.,

$$
m c_{t}(i)=\frac{1}{\kappa} \frac{w_{t} l_{t}(i)}{y_{t}(i)} .
$$

Of course, since all firms face the same rental prices for capital and labor and are subject to the same aggregate technology shock, they employ capital and labor in the same ratio and share the same real marginal costs. Therefore,

$$
m c_{t}(i)=\frac{1}{\kappa} \frac{w_{t} l_{t}}{y_{t}}
$$

Log-linearizing equation (D1) implies

$$
\widehat{m c}_{t} \simeq \widehat{w}_{t}+\widehat{l}_{t}-\widehat{y}_{t}
$$

Equation (D2) establishes that, to a first-order log-linear approximation, aggregate real marginal costs depend on the consumption real wage and the aggregate marginal productivity of labor.

The firm-level production function is given by,

$$
y_{t} \equiv\left[\int_{0}^{1} y_{t}(i)^{\frac{\epsilon-1}{\epsilon}} d i\right]^{\frac{\epsilon}{\epsilon-1}}=\left[\int_{0}^{1}\left(\left[e^{u_{t}} l_{t}(i)\right]^{\kappa} k_{t}(i)^{1-\kappa}\right)^{\frac{\epsilon-1}{\epsilon}} d i\right]^{\frac{\epsilon}{\epsilon-1}}
$$

which, when log-linearized yields

$$
\widehat{y}_{t} \simeq u_{t}+\widehat{l}_{t}+(1-\kappa)\left(\widehat{k}_{t}-\widehat{u}_{t}-\widehat{l}_{t}\right) .
$$

To proceed further, I consider the limiting case in which $\kappa \uparrow 1$ and the role of capital in production tends to zero. Under this assumption the log-linearized resource constraint is $\widehat{c}_{t}=\widehat{y}_{t}$. Combining equations (D2) and (D3) with (a log-linearized) equation (C3), the expression for real marginal costs becomes

$$
\widehat{m c}_{t}=\chi \widehat{y}_{t}-(1+\chi) u_{t}-\widehat{\lambda}_{t} .
$$

Now log-linearizing equation $(\mathrm{C} 2)$ yields

$$
\widehat{\lambda}_{t}=-\frac{\sigma}{(1-\gamma)}\left(\widehat{c}_{t}+\gamma \widehat{c}_{t-1}\right)+g_{t}
$$

implying that real marginal costs equal

$$
\widehat{m c}_{t}=\left[\chi+\frac{\sigma}{(1-\gamma)}\right] \widehat{c}_{t}-\frac{\sigma \gamma}{(1-\gamma)} \widehat{c}_{t-1}-(1+\chi) u_{t}-g_{t},
$$

which is equation (21) in the text.

\section{References}

[1] Altig, D., Christiano, L., Eichenbaum, M., and J. Linde, (2004), "Firm-Specific Capital, Nominal Rigidities, and the Business Cycle," Northwestern University, manuscript. 
[2] Amato, J., and T. Laubach, (2003), "Estimation and Control of an Optimization-Based Model with Sticky Prices and Wages," Journal of Economic Dynamics and Control, 27, pp. 1181-1215.

[3] Bils, M., and P. Klenow, (2004), "Some Evidence on the Importance of Sticky Prices," Journal of Political Economy, 112, pp. 947-985.

[4] Blinder, A., (1994), "On Sticky Prices: Academic Theories Meet the Real World," in Mankiw, N. G. (ed), Monetary Policy, University of Chicago Press, Chicago, pp. 117-150.

[5] Calvo, G., (1983), "Staggered Contracts in a Utility-Maximising Framework," Journal of Monetary Economics, 12, pp. 383-398.

[6] Carlton, D., (1986), "The Rigidity of Prices," American Economic Review, 76, 4, pp. 637-658.

[7] Cecchetti, S., (1986), "The Frequency of Price Adjustment: A Study of the Newsstand Prices of Magazines," Journal of Econometrics, 31, pp. 255-274.

[8] Chang, Y., and S-B. Kim, (2005), "On the Aggregate Labor Supply," Federal Reserve Bank of Richmond Economic Quarterly, 91, pp. 21-37.

[9] Cho, S., and A. Moreno, (2005), "A Small-Sample Study of the New Keynesian Macro Model," Journal of Money, Credit, and Banking, 38, 6, pp. 1461-1481.

[10] Christiano, L., Eichenbaum, M., and C. Evans, (2005), "Nominal Rigidities and the Dynamic Effects of a Shock to Monetary Policy," Journal of Political Economy, 113, pp. $1-45$.

[11] Clarida, R., Galí, J., and M. Gertler, (1998), "Monetary Policy Rules in Practice: Some International Evidence," European Economic Review, 42, pp. 1037-1067.

[12] Clarida, R., Galí, J., and M. Gertler, (1999), "The Science of Monetary Policy: A New Keynesian Perspective," Journal of Economic Literature, 37, 4, pp. 1661-1707.

[13] Clarida, R., Galí, J., and M. Gertler, (2000), "Monetary Policy Rules and Macroeconomic Stability: Evidence and Some Theory," The Quarterly Journal of Economics, February, pp. 147-180.

[14] Dixit, A., and J. Stiglitz, (1977), "Monopolistic Competition and Optimum Product Diversity," American Economic Review Papers and Proceedings, 67, pp. 297-308.

[15] Dennis, R., (2006), "The Policy Preferences of the U.S. Federal Reserve," Journal of Applied Econometrics, 21, pp. 55-77.

[16] Dennis, R., (2009), "Consumption-Habits in a New Keynesian Business Cycle Model," Journal of Money, Credit, and Banking, 41, 5, pp. 1015-1030.

[17] Del Negro, M., and F. Schorfheide, (2008), "Forming Priors for DSGE Models (and How it Affects the Assessment of Nominal Rigidities)," Journal of Monetary Economics, 55, pp. 1191-1208.

[18] Dupor, W., Kitamura, T., and T. Tsuruga, (2008), "Integrating Sticky Prices and Sticky Information," Review of Economics and Statistics, forthcoming.

[19] Eichenbaum, M., and J. Fisher, (2004), "Evaluating the Calvo Model of Sticky Prices," National Bureau of Economic Research Working Paper \#10617.

[20] Eichenbaum, M., and J. Fisher, (2007), "Estimating the Frequency of Price Reoptimization in Calvo-Style Models," Journal of Monetary Economics, 54, pp. 2032-2047. 
[21] Estrella, A., and J. Fuhrer, (2002), "Dynamic Inconsistencies: Counterfactual Implications of a Class of Rational-Expectations Models," American Economic Review, 92, 4, pp. 1013-1028.

[22] Favero, C., and R. Rovelli, (2003), "Macroeconomic Stability and the Preferences of the Fed. A Formal Analysis, 1961-98," Journal of Money, Credit, and Banking, 35, pp. 545556.

[23] Fuhrer, J., (2000), "Optimal Monetary Policy in a Model with Habit Formation," American Economic Review, 90, 3, pp. 367-390.

[24] Galí, J., and M. Gertler, (1999), "Inflation Dynamics: A Structural Econometric Analysis," Journal of Monetary Economics, 44, pp. 195-222.

[25] Galí, J., Gertler, M., and D. López-Salido, (2001), "European Inflation Dynamics," European Economic Review, 45, pp. 1237-1270.

[26] Gelfand, A., and D. Dey, (1994), "Bayesian Model Choice: Asymptotics and Exact Calculations," Journal of the Royal Statistical Society Series B, 56, pp. 501-514.

[27] Gelman, A., (1995), "Inference and Monitoring Convergence," in Gilks, W., Richardson, S., and D. Spiegelhalter, (eds), Practical Markov Chain Monte Carlo, Chapman and Hall Press, London, pp. 131-143.

[28] Gertler, M., and J. Leahy, (2008), "A Phillips Curve with an Ss Foundation," Journal of Political Economy, 116, 3, pp. 533-572.

[29] Geweke, G., (1992), "Evaluating the Accuracy of Sampling-Based Approaches to the Calculation of Posterior Moments," in Bernardo, J., Dawid, A., and A. Smith (eds), Bayesian Statistics, Clarendon Press, Oxford, 4, pp. 641-649.

[30] Geweke, G., (1999), "Using Simulation Methods for Bayesian Econometric Models: Inference, Development, and Communication," Econometric Reviews, 18, pp. 1-126.

[31] Giannoni, M., and M. Woodford, (2003), "How Forward-Looking is Optimal Monetary Policy?" Journal of Money, Credit, and Banking, 35, 6, pp. 1425-1469.

[32] Jondeau, E., and H. Le Bihan, (2005), "Testing for the New Keynesian Phillips Curve. Additional International Evidence," Economic Modelling, 22, pp. 521-550.

[33] Jung, Y., and T. Yun, (2005), "Implications of Inventory Models for the New Keynesian Phillips Curve," Kyunghee University, manuscript.

[34] Kashyap, A., (1995), "Sticky Prices: New Evidence from Retail Catalogs," The Quarterly Journal of Economics, February, pp. 245-274.

[35] Kim, J., (2000), "Constructing and Estimating a Realistic Optimizing Model of Monetary Policy," Journal of Monetary Economics, 45, pp. 329-359.

[36] Laubach, T., and J. Williams, (2003), "Measuring the Natural Rate of Interest," Review of Economics and Statistics, 85, 4, pp. 1063-1070.

[37] Levin, A., Onatski, A., Williams, J., and N. Williams, (2006), "Monetary Policy Under Uncertainty in Micro-Founded Macroeconometric Models," in Gertler, M., and K. Rogoff (eds), NBER Macroeconomics Annual 2005, MIT Press, Cambridge, Massachusetts, pp. 229-287.

[38] Liu, Z., and L. Phaneuf, (2007), "Technology Shocks and Labor Market Dynamics: Some Evidence and Theory," Journal of Monetary Economics, 54, pp. 2534-2553. 
[39] Lucas, R., (1976), "Econometric Policy Evaluation: A Critique," Carnegie-Rochester Conference Series on Public Policy, 1, pp. 19-46.

[40] Mankiw, N. G., (1985), "Small Menu Costs and Large Business Cycles: A Macroeconomic Model of Monopoly," The Quarterly Journal of Economics, May, pp. 529-537.

[41] Mankiw, N. G., and R. Reis, (2002), "Sticky Information Versus Sticky Prices: A Proposal to Replace the New Keynesian Phillips Curve," The Quarterly Journal of Economics, 117, 4, pp. $1295-1328$.

[42] McCallum, B., and E. Nelson, (1999), "Nominal Income Targeting in an Open-Economy Optimizing Model," Journal of Monetary Economics, 43, pp. 553-578.

[43] Nakamura, E., and J. Steinsson, (2008), "Five Facts About Prices: A Reevaluation of Menu Cost Models," The Quarterly Journal of Economics, 23, 4, pp. 1415-1464.

[44] Rabanal, P., and J. Rubio-Ramírez, (2005), "Comparing New Keynesian Models of the Business Cycle: A Bayesian Approach," Journal of Monetary Economics, 52, pp. 11511166.

[45] Ravenna, F., and C. Walsh, (2006), "Optimal Monetary Policy and the Cost Channel," Journal of Monetary Economics, 53, 2, pp. 199-216.

[46] Roberts, J., (1995), "New Keynesian Economics and the Phillips Curve" Journal of Money, Credit, and Banking, 27, 4, pp. 975-984.

[47] Rotemberg, J., (1982), "Sticky Prices in the United States," Journal of Political Economy, 60, pp. 1187-1211.

[48] Rotemberg, J., and M. Woodford, (1997), "An Optimization-Based Econometric Framework for the Evaluation of Monetary Policy," in Bernanke, B., and J. Rotemberg, (eds) NBER Macroeconomics Annual 1997, MIT Press, Cambridge.

[49] Rudd, J., and C. Whelan, (2006), "Can Rational Expectations Sticky-Price Models Explain Inflation Dynamics?" American Economic Review, 96, 1, pp. 303-320.

[50] Sahuc, J-G., (2004), "Partial Indexation and Inflation Dynamics: What do the Data Say?" Applied Economics Letters, 11, pp. 827-832.

[51] Sbordone, A., (2002), "Prices and Unit Labor Costs: A New Test of Price Stickiness," Journal of Monetary Economics, 49, pp. 265-292.

[52] Sims, C., (2003), "Implications of Rational Inattention," Journal of Monetary Economics, 50, pp. 665-690.

[53] Smets, F., (2003), "Maintaining Price Stability: How Long is the Medium Term," Journal of Monetary Economics, 50, pp. 1293-1309.

[54] Smets, F., and R. Wouters, (2003), "An Estimated Dynamic Stochastic General Equilibrium Model of the Euro Area," Journal of the European Economic Association, 1, 5, pp. $1123-1175$.

[55] Smets, F., and R. Wouters, (2005), "Comparing Shocks and Frictions in US and Euro Area Business Cycles: A Bayesian DSGE Approach," Journal of Applied Econometrics, 20, pp. 161-183.

[56] Smets, F., and R. Wouters, (2007), "Shocks and Frictions in US Business Cycles: A Bayesian DSGE Approach," American Economic Review, 97, 3, pp. 586-606. 
[57] Taylor, J., (1980), "Aggregate Dynamics and Staggered Contracts," Journal of Political Economy, 88, pp. 1-24.

[58] Walsh, C., (2003), "Speed Limit Policies: The Output Gap and Optimal Monetary Policies," American Economic Review, 93, 1, pp. 265-278.

[59] Woodford, M., (2003), Interest and Prices, Princeton University Press, Princeton, New Jersey.

[60] Woodford, M., (2008), "Information-constrained State Dependent Pricing," manuscript (version dated June 25, 2009).

[61] Zbaraki, M., Ritson, M., Levy, D., Dutta, S., and M. Bergin, (2004), "Managerial and Customer Costs of Price Adjustment: Direct Evidence from Industrial Markets," Review of Economics and Statistics, 86, 2, pp. 514-533.

[62] Zbaraki, M., Levy, D., and M. Bergin, (2007), "The Anatomy of a Price Cut: Discovering Organizational Sources of the Costs of Price Adjustment," Manuscript. 